Research Article

\title{
The Configuration of Supply Chain Concentration and Staff Structure in Intelligent Manufacturing: A Fuzzy Sets Qualitative Comparative Analysis
}

\author{
Jie Ding $\mathbb{D}^{1},{ }^{1}$ Siqi Wang $\mathbb{D}^{1},{ }^{1}$ and Meilan Chen $\mathbb{D}^{2}$ \\ ${ }^{1}$ School of Finance, Fujian Jiangxia University, Fuzhou, China \\ ${ }^{2}$ Guangdong University of Finance \& Economics, Guangzhou, China \\ Correspondence should be addressed to Jie Ding; dingjie035@fjjxu.edu.cn
}

Received 26 July 2021; Accepted 14 September 2021; Published 14 December 2021

Academic Editor: Lei Xie

Copyright (C) 2021 Jie Ding et al. This is an open access article distributed under the Creative Commons Attribution License, which permits unrestricted use, distribution, and reproduction in any medium, provided the original work is properly cited.

\begin{abstract}
In traditional manufacturing enterprises, there are common problems of low added value of products, low profit, and poor business performance. As a result, they endeavor to transform themselves into intelligent manufacturing. To help with their transformation, this paper proposes a decision support model for managers to improve the business performance under different configurations of supply chain concentration and staff structure. Through the fuzzy set qualitative comparative analysis, the membership degree is given to the variables, and then the configuration analysis is carried out. We find that, to facilitate intelligent manufacturing, the concentration degree of supply chain or the structure of employee education should be adjusted according to the results from the qualitative comparative analysis of fuzzy sets. Two configuration paths to improve business performance are found. When the supply chain concentration degree is relatively decentralized, manufacturing enterprises should expand the proportion of sales personnel and production personnel. In other words, when the sales personnel and production personnel reach the saturation state, low concentration of suppliers and customers is more conducive to the improvement of business performance. The configuration of high proportion of production personnel and low customer concentration tends to lock enterprises in the lower end of the value chain. Therefore, it is critical for enterprises to improve the education level of employees to transform into intelligent manufacturing and improve their business performance.
\end{abstract}

\section{Introduction}

In recent years, China's economy has shifted from the mode of high-speed growth to high-quality development. For example, the gross production value of Chinese manufacturing industry from 2013 to 2016 accounted for about $30 \%$ of the GDP. Currently, while China's economy continues to develop, it has endeavored to improve the performance of its manufacturing industry. However, China is still in the critical period of development mode transformation. As a result, refining the economic structure and transforming the driving force of growth, environmental protection, kinetic energy conversion, technological upgrading, and other factors have formed a multidirectional squeeze on the transformation and upgrading of manufacturing enterprises, which are still faced with issues such as serious environmental pollution, imbalance of supply structure, and difficulty in tackling key technologies [1]. In an era of global calls for green environment protection, the profit margin of Chinese manufacturing industry has been shrinking. At the same time, the international competition in manufacturing has become increasingly fierce, which is reflected by the "reindustrialization" strategies in the developed countries, such as the "Advanced Manufacturing Partnership Program" in the United States, the "Industrial 4.0" and "National Industrial Strategy 2030" in Germany, the "New Industry France" in France, and the "Rejuvenation Strategy" in Japan, and the industrial layout adjustment in developing countries, with industries and capital gradually shifting to countries such as Vietnam, India, and Cambodia. In the meantime, worldwide economic growth continues to slow 
down, trade protectionism is rising, antiglobalisation is prevailing, foreign demand markets are depressed, and risk challenges are increasing [2]. The situation of "internal and external troubles" prevents Chinese manufacturing enterprises from improving their business performance. At the Central Economic Work Conference in 2019, "focus on promoting high-quality development" was regarded as one of the six major tasks, and special measures for manufacturing industry development are proposed, such as increasing medium and long-term financing of manufacturing industry, promoting the transformation and upgrading of traditional manufacturing enterprises and profit growth, and creating a number of advanced manufacturing industry clusters with international competitiveness, which shows that the high-quality development of manufacturing enterprises plays and will play an important role in China's economic development at present and in the future for a long time. Therefore, how to effectively improve the business performance of manufacturing enterprises has become a hot spot of concern for current scholars. It is urgent to improve the operating performance of manufacturing enterprises and accelerate the transformation from traditional manufacturing industry to intelligent manufacturing.

Under the situation of rapid product renewal and replacement cycle, diversified consumer demand and continuous development of individualization, it has been difficult for manufacturing enterprises to adapt to the changing manufacturing market by relying on their own internal resources to independently develop and improve their business performance. In order to achieve sustainable development, enterprises must cooperate with the outside world to obtain appropriate resources and information, for which supply chain is an important channel, whose structural characteristics can affect the competitiveness of enterprises [3]. Supply chain concentration is an important feature of enterprise supply chain structure, including customer concentration and supplier concentration [4]. Qrunfleh et al. [5] believe that close supply chain partnerships can have a positive impact on business performance and that centralization strategies can help businesses capture markets and accumulate resources [6]. Meanwhile, some scholars believe that higher concentration may lead to the loss of enterprise independence and increase the business risk of enterprises [7]. Huang et al. [8] found that the impact of upstream and downstream supply chain concentration on enterprise R\&D innovation is different: customer concentration plays a promoting role, but supplier concentration plays a suppressive role, and the innovation ability of manufacturing enterprises is one of the important capabilities that enterprises need to improve. Thus, it is clear that the impact of supply chain concentration on the business performance of manufacturing enterprises needs to be further discussed under different circumstances. In addition, different staff structures in enterprises will also have an important impact on business performance. Yang et al. [9] found through empirical research that the educational background structure of employees will have a certain effect and influence on the business performance of enterprises. In labor-intensive enterprises, the proportion of shareholding and income of senior managers are significantly positively correlated with the business performance of enterprises, but not in capital intensive and technology intensive enterprises. Liu et al. [10] found that, according to the nature, scale, and stage of development of the enterprise, the contribution of managers and producers to business performance may vary greatly. Empirical analysis made by Chen et al. [11] on the impact of employee knowledge structure on business performance shows that employee knowledge structure has a significant positive impact on business performance, and the stronger the positive impact when the external environment changes sharply.

It can be seen that the literature so far has explored the role and impact of different supply chain concentration or different staff structure on the business performance of manufacturing enterprises. However, there is a lack of research on supply chain concentration and staff structure of manufacturing enterprises jointly, and the mechanism of their combined effect on the operating performance of manufacturing enterprises is not made clear. It is worth noting that, in real life, a single outcome is often produced by several factors together [12]. The change of staff structure in manufacturing enterprises and the choice of different supply chain concentration degree will have different impacts on strategic decisions and objectives of enterprises. Fuzzy Set Qualitative Comparative analysis (fsQCA) provides a way to drill down into the data to reveal the fine details of the complexity of entrepreneurial phenomena. The fsQCA method is compatible with data asymmetry and potential interdependence of variables. It can identify asymmetric data relationships and reveal multiple equivalence paths for the same result. FsQCA examines relationships between antecedent variables (called conditions) within a case and analyzes relationships between dependent variables (called outcomes) and specific combinations of conditions (called configurations). It finds common configurations of multiple cases, and these different common configurations constitute specific pathways to specific outcomes. Thus, FsQCA complements traditional symmetric approaches by adding a more nuanced understanding of entrepreneurial phenomena and providing an empirical basis for abductive analysis. Therefore, in this paper, the data of Chinese Manufacturing Listed Companies in 2017 are selected as samples, and the following research questions are empirically tested by fsQCA: (1) What are the effective combinations of staff structures and supply chain concentration to improve business performance? (2) How should manufacturing enterprises with different degrees of supply chain concentration change with the structure of their employees?

Our contributions of this paper include the followings. Frist, we add configuration model to analyze the impact of supply chain concentration on business performance considering configuration effect, which enriches the research work of supply chain concentration. Second, we consider different staff structures of different manufacturing enterprises, which makes the conclusions more realistic and can provide better decision support tools for manufacturing 
enterprises to improve their business performance. Third, our research provides a technological path for traditional manufacturing enterprises to transform themselves into intelligent manufacturing. Fourth, this paper uses the qualitative analysis method of fuzzy set to more effectively analyze the interactive relationship between customer concentration and employee structure. Through the crosssectional data and the data of 39 listed companies from different industries, the conclusion is more robust.

\section{Theoretical Analysis and Research Hypotheses}

With the improvement of economic development and marketing level, most enterprises will actively establish longterm and stable customer cooperation to improve business performance. However, if the customer concentration is too high, business risks will increase, and the production and operation decisions of enterprises will be affected. As the main stakeholders and participants of enterprise production and operation, customers are an important source of enterprise income. The higher the customer concentration is, the greater the risk the enterprise will suffer in the process of operation. Excessive reliance on key customers will lead to excessive concentration of risks, which is an important incentive to change the business direction of enterprises or lead to bankruptcy or bankruptcy of enterprises or further affect the current investment decisions and business performance of enterprises and even continue to affect the subsequent development and investment choice of enterprises [13]. In the process of enterprise operation, if the concentration of key customers is too high, it will inhibit the development of enterprises. Especially, when big customers are in debt to enterprises and increase their commercial credit, financial risks of big customers will inevitably lead to significant financial losses of enterprises, thus affecting the normal capital operation of enterprises [14]. Cao and Tao [15] found that the staff structure of enterprises needs to be constantly adjusted according to the development of external information technology, which will have a certain impact on the business performance of enterprises. Xiao et al. [16] believed that, in the initial stage of enterprise upgrading, the focus needs to be shifted from manufacturing to marketing, and the proportion of salespeople can reflect the advancement of employees. For most manufacturing enterprises, production is still their main activity, so the proportion of production personnel in manufacturing enterprises tends to be larger. Thus, the following hypothesis is proposed:

$\mathrm{H} 1$ : for manufacturing enterprises, production personnel play a key role in the type of configuration that produces high corporate performance

At this stage, the performance of manufacturing enterprises cannot be improved with a single production activity, so enterprises need to change their staff structure. In addition to increasing the proportion of sales staff, the quality of employees in an enterprise can also reflect the advancement of staff structure: the higher the quality of employees, the stronger the competitiveness of the enterprise. Besides, the educational background structure of employees (the proportion of employees with bachelor's degree or above) can reflect the comprehensive quality of employees. At present, most manufacturing enterprise managers believe that production activity is a nonacademic activity and tend to choose cheaper labor to reduce costs. In contrast, Zhao et al. [17] found that employee education contributes to sales and total assets of an enterprise, which shows that the education level of employees of an enterprise has a great influence on the economic benefits of the enterprise. Thus, employees, as the backbone of the enterprise, will have different impacts on the enterprise due to their structural changes. When making different decisions, enterprise decision makers need to consider the staff structure of their own enterprise in order to find the most suitable staff structure for their own development.

Wang et al. [18] argued that the "bargaining mechanism" of manufacturing enterprises may change their business performance. The fluctuation of raw material price is one of the key issues concerned by manufacturing enterprises. Since upstream and downstream supply chain partners may refuse to bear the risk of price rises and thus exert pressure on enterprises, decentralizing supply chain partnerships can alleviate economic pressures and disperse business risks. In this context, the decentralized supply chain partnership needs to expand the proportion of sales personnel to enhance the marketing ability of the enterprise. Therefore, when the supply chain concentration of an enterprise is relatively decentralized, it needs to expand the proportion of salespeople to improve business performance. Close supply chain partnerships can help companies gain market share and reduce transaction costs to some extent [19]. As a result, enterprises with high supply chain concentration can get more market resources and improve their competitive position, thus expanding the scale of enterprises and increasing the proportion of production personnel. But at the same time, they will often face greater risks; for example, largescale production personnel may lead to low staff structure, thus locking the value of products produced by enterprises at the low end of the value chain, so it is necessary to improve the employee's educational background structure. Thus, the following hypotheses are proposed:

$\mathrm{H} 2$ : the configuration of low supply chain concentration and high proportion of sales personnel can improve the performance of manufacturing enterprises

H3: high supply chain concentration needs to be configured with high proportion of production personnel and high education background to improve the manufacturing business performance

\section{Research Design}

3.1. Methodology. Qualitative comparative analysis (QCA) is a case-oriented method proposed by Ragin, an American sociologist, for small- and medium-sized samples [20]. It focuses on the multiple causal conjunctures produced by a result and explores which factors are grouped together to 
cause such result [21]. In this paper, fsQCA in QCA is selected for empirical research, mainly because (1) it is suitable for the study on 10-80 small- and medium-sized samples and requires fewer samples than traditional regression analysis to ensure reliable conclusions; (2) it is improved on the qualitative comparison method of clear set (or Cantor set), assigning a membership of $0-1$ to each variable instead of simply attributing the variable to 0 (failure) or 1 (success), which ensures the integrity of sample information in the process of converting to data; (3) the result of a phenomenon is a combination of many factors, and the supply chain concentration studied in this paper will have different effects on business performance under different staff structures, so further analysis is needed.

3.2. Data Sources. In this paper, the data of 44 listed manufacturing enterprises in 2017 are selected as the basic sample, and the enterprises lacking key data, ST, and delisting are eliminated. Finally, the sample data of 39 listed manufacturing enterprises are screened out. Among them, the enterprise sample data are all derived from the authoritative database of China, CSMAR database, and are checked with the annual reports of sample enterprises and the data published on the CNINFO, thus ensuring the validity of the samples, enriching sample data, and providing more effective data support for analysis.

\subsection{Variable Selection}

(1) One outcome variable: business performance (business_p). Following the measurement method of $\mathrm{Hu}$ and $\mathrm{Xu}[20]$, the enterprise's business performance is measured by the proportion of total profit to total assets.

(2) Five conditional variables: (1) customer concentration (customer_c), measured by the proportion of the total sales of the top five customers to the total annual sales; (2) supplier concentration (supplier_c), expressed by the proportion of the total top five purchase amount of the enterprise to the total annual purchase amount; (3) proportion of production personnel (proportion $-p$ ), measured by the proportion of the production personnel to total employees in the enterprise; (4) proportion of sales personnel (proportion_s), measured by the proportion of the sales personnel to total employees in the enterprise; and (5) staff education (staff_e), measured by the proportion of employees with bachelor's degree or above.

3.4. Variable Calibration. The fsQCA3.0 software was used to calibrate the variables: (1) Calibrate the outcome variable (business performance) and five conditional variables (customer concentration, supplier concentration, production personnel proportion, sales personnel proportion, and staff education structure) and convert them to $0-1$ fuzzy set membership. (2) Set three critical values: full membership, intersection, and full nonmembership [22]. The anchor points for each critical value are set to the 75,50 , and 25 quantile values [23] of the sample data, respectively. The three anchor points for each variable are shown in Table 1. (3) Set the consistency threshold to 0.8 according to Fiss [24].

\section{Empirical Analysis}

4.1. Analysis of Necessary Conditions. The consistency of each conditional variable to the outcome variable should be checked before the configuration analysis of supply chain concentration and staff structure. When the consistency reaches above 0.9 , it is considered that the conditional variable will inevitably lead to this result. In this paper, the necessity test of business performance of the sample enterprise is shown in Table 2.

Table 2 shows that the consistency score of the five conditional variables on business performance is between 0.44 and 0.63 , That is, these factors do not cause the improvement of business performance. And there is no single sufficiency to improve business performance. It is thus clear that single conditional variable does not have strong explanatory power to improve business performance, and configuration needs to be further analyzed.

In this paper, scatter plots of business performance are drawn from the perspectives of staff structure and supply chain concentration, as shown in Figure 1. In Figure 1(a), the size of bubbles represents the business performance of the enterprise, and the larger the bubble, the better the business performance, and the denser bubbles are located in the upper left corner and the lower right corner, which can preliminarily reflect that the advancement of staff structure can have a positive impact on the business performance and that the manufacturing enterprises with a high proportion of production personnel have better business performance. It can be seen from Figure 1(b) that bubbles are evenly distributed. Under the premise of high business performance, bubbles are concentrated in regions with low supplier concentration and low customer concentration, indicating that bubbles mainly appear in regions with low supply chain concentration. Configuration analysis is needed after combining staff structure with supply chain concentration for specific conclusions.

4.2. Configuration Analysis. After processing data variables with fsQCA software, three solutions are obtained: complex solution, intermediate solution, and parsimonious solution. Complex solution refers to the solution that does not have any "logical remainder," whereas "logical remainder" refers to combinations of conditions that lack empirical instances. Intermediate solution refers to the solution obtained by eliminating unreasonable "logical remainder" only with the help of those "logical remainder," which are consistent with research theory and practical experience. Parsimonious solution is one that is obtained by virtue of all the "logical remainders" [22]. Because the rationality of "logical remainder" is not considered in the parsimonious solution, 
TABLE 1: Calibration anchors for the variables.

\begin{tabular}{lcccc}
\hline & \multirow{2}{*}{ Variables (in percentage) } & & \multicolumn{2}{c}{ Anchor points } \\
& & Full membership & Intersection & Full nonmembership \\
\hline Outcome variable & Business performance & 6.81 & 4.93 & 2.98 \\
\hline & Customer concentration & 37.26 & 23.80 & 14.94 \\
Conditional variables & Supplier concentration & 30.07 & 21.09 & 15.12 \\
& Proportion of production personnel & 71.57 & 63.32 & 51.53 \\
& Proportion of sales personnel & 12.57 & 4.96 & 2.78 \\
& Staff education structure & 38.54 & 21.00 & 12.82 \\
\hline
\end{tabular}

TABle 2: Necessity test of business performance.

\begin{tabular}{|c|c|c|c|}
\hline Variables & Meaning & Consistency & Coverage \\
\hline customer_c & High customer concentration & 0.4475 & 0.4626 \\
\hline$\sim$ customer_c & Low customer concentration & 0.6308 & 0.6363 \\
\hline supplier_c & High supplier concentration & 0.5394 & 0.5400 \\
\hline$\sim$ supplier_c & Low supplier concentration & 0.5449 & 0.5678 \\
\hline proportion $_{-} p$ & High proportion of production personnel & 0.5916 & 0.5905 \\
\hline$\sim$ proportion $\_p$ & Low proportion of production personnel & 0.5002 & 0.5228 \\
\hline proportion_s & High proportion of sales personnel & 0.5565 & 0.5735 \\
\hline$\sim$ proportion $\_s$ & Low proportion of sales personnel & 0.5334 & 0.5396 \\
\hline staff_e & High staff education level & 0.4967 & 0.5346 \\
\hline$\sim$ staff_e & Low staff education level & 0.5706 & 0.5541 \\
\hline
\end{tabular}

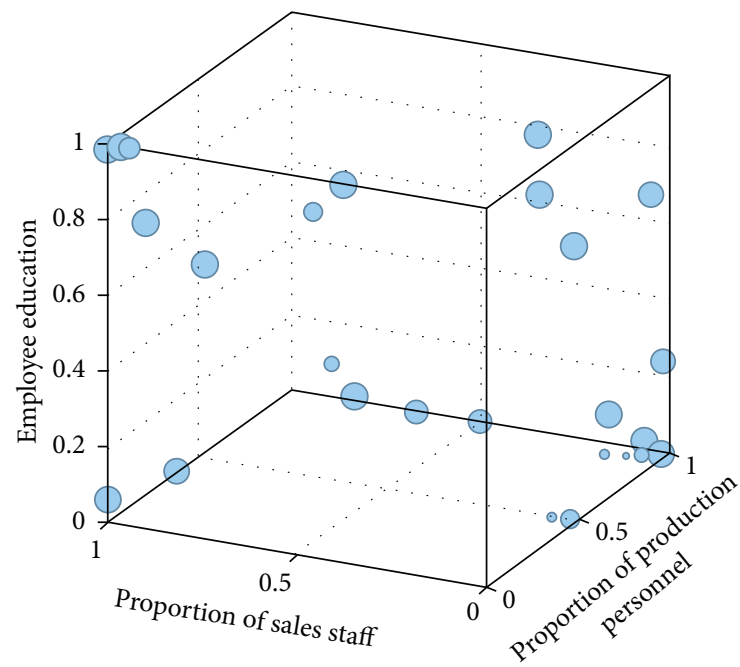

(a)

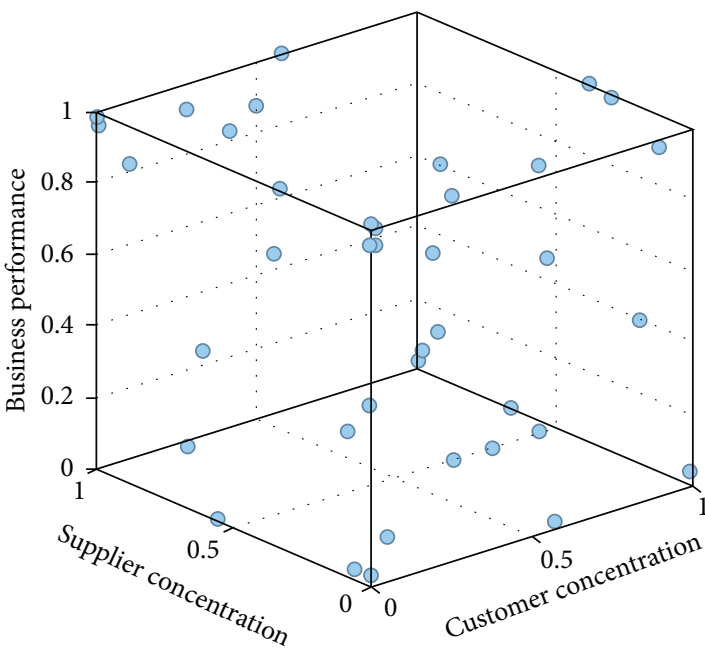

(b)

FIGURE 1: Scatter plots from (a) the perspective of staff structure and (b) the perspective of supply chain concentration.

and the complex solution conditions are the most demanding, which sometimes do not conform to the actual situation, most scholars will choose the intermediate solution for research [25]. In addition, the conditional variables that appear simultaneously in the intermediate solution as well as in the parsimonious solution are the core conditions, and the conditional variables that appear only in the intermediate solution but not in the parsimonious solution are the auxiliary conditions [26]. In this paper, the results obtained after the configuration analysis of 39 sample data are shown in Table 3. In Table 3, symbol - indicates the existence of the conditional variable, $\otimes$ indicates the absence of the conditional variable, $\bullet$ indicates the core condition, and $\bullet$ indicates the auxiliary condition [27].

Table 3 shows that there are two configuration paths to improve the business performance of manufacturing enterprises. The consistency of the two solutions is $80 \%$ and $84 \%$, respectively, and the solution consistency reaches $87 \%$, 
TABLE 3: The effective configurations to achieve high performance of manufacturing enterprises.

\begin{tabular}{lcc}
\hline Configuration & \multicolumn{2}{c}{ Solutions } \\
& 1 & 2 \\
\hline Customer concentration & $\otimes$ & $\otimes$ \\
Supplier concentration & $\otimes$ & \\
Proportion of production personnel & $\bullet$ & $\bullet$ \\
Proportion of sales personnel & $\bullet$ & \\
Staff education structure & & $\bullet$ \\
Consistency & 0.80 & 0.84 \\
Raw coverage & 0.15 & 0.19 \\
Unique coverage & 0.08 & 0.11 \\
Solution consistency & 0.87 & \\
Solution coverage & 0.27 & \\
\hline
\end{tabular}

so all these configuration solutions have strong explanatory power to improve the business performance. The configuration of high production personnel and low customer concentration occurs in both solutions as the core condition. To further verify the explanatory power of these solutions to business performance, a configuration $\mathrm{X}-\mathrm{Y}$ scatter plot is drawn as shown in Figure 2 that most of the samples are distributed at the top left of the diagonal line, which proves that both configuration solutions are sufficient conditions to improve business performance combining with the solution consistency.

The detailed analysis of the two configuration solutions is as follows:

(1) Solution 1: improving enterprise performance $=$ low supply chain concentration + high proportion of production personnel + high proportion of sales personnel (proportion_p $*$ proportion_s $* \sim$ cust omer $_{-}$* $\sim$ supplier $\_$), which shows that the decision makers can improve the business performance by choosing to expand the proportion of production and sales personnel in case of low supply chain concentration. Similarly, when the enterprise has a high proportion of production and sales personnel, centralization strategy is no longer applicable, and decision makers should choose a decentralized supply chain partnership. The solution is applicable to $15 \%$ of cases and achieves $80 \%$ consistency. Solution 1 supports $\mathrm{H} 2$, but it needs to be supplemented. That is, manufacturing enterprises with low supply chain concentration and high proportion of sales personnel must configure with the high proportion of production personnel in order to improve the business performance of manufacturing enterprises. First of all, the low supply chain concentration must cooperate with the high proportion of sales personnel in order to play an advantage, which is particularly important for customer concentration. Enterprises must have strong marketing ability if they want to expand the customer base, so expanding the proportion of sales personnel is the decision that enterprises must choose. Although the dispersed supplier group and customer group can help the enterprise to improve its risk resistance, the enterprise must increase the proportion of production personnel to meet the production demand because of the dispersed relationship network and more partners. Secondly, for manufacturing enterprises with low supply chain concentration and high proportion of production personnel, enterprise decision makers can choose to increase the proportion of sales personnel to improve business performance. In Solution 1, low customer concentration, low supplier concentration, and high proportion of production personnel are the core conditions, while the high proportion of sales personnel is the auxiliary conditions. However, without high proportion of sales personnel, the solution will not work. Therefore, in enterprises with dispersed supply chain partnerships and high proportion of production personnel, choosing to increase the proportion of sales personnel to optimize the structure of enterprise employees can help enterprises improve their own business performance.

(2) Solution 2: improving corporate performance $=$ low customer concentration + high proportion of production personnel + high employee education level (proportion_p $*$ staff $f_{-} e * \sim$ customer_c), which shows that when the enterprise has a low customer concentration and a high proportion of production personnel, it should optimize the structure of employee academic qualifications to improve employee academic qualifications, in order to improve business performance. The solution is applicable to $19 \%$ of cases and achieves $84 \%$ consistency. Solution 2 fails to validate $\mathrm{H} 3$, so $\mathrm{H} 3$ does not hold. Compared with solution 1, it is found that the configuration of proportion_ $p * \sim$ customer $_{-} c$ appears in both solutions as the core condition. It follows that the configuration with high proportion of production personnel and low customer concentration is the common feature in most manufacturing enterprises, which can also indirectly reflect that Chinese manufacturing enterprises are still in the stage of mass production of low-value products and have a low position in the value chain. In this case, decision makers can help enterprises to upgrade and improve business performance by introducing highend talents, optimizing the education structure of employees, and improving the overall quality of employees. However, when the enterprise has higher education level and higher proportion of production personnel, the impact of supplier concentration on the enterprise is not significant, and decision makers can choose to disperse the customer base to expand profits. In Solution 2, low customer concentration, high proportion of production personnel, and high staff education are the core conditions. In addition, Table 3 shows that the production personnel are the core conditions in both path solutions. Thus, $\mathrm{H} 1 \mathrm{can}$ be verified. 


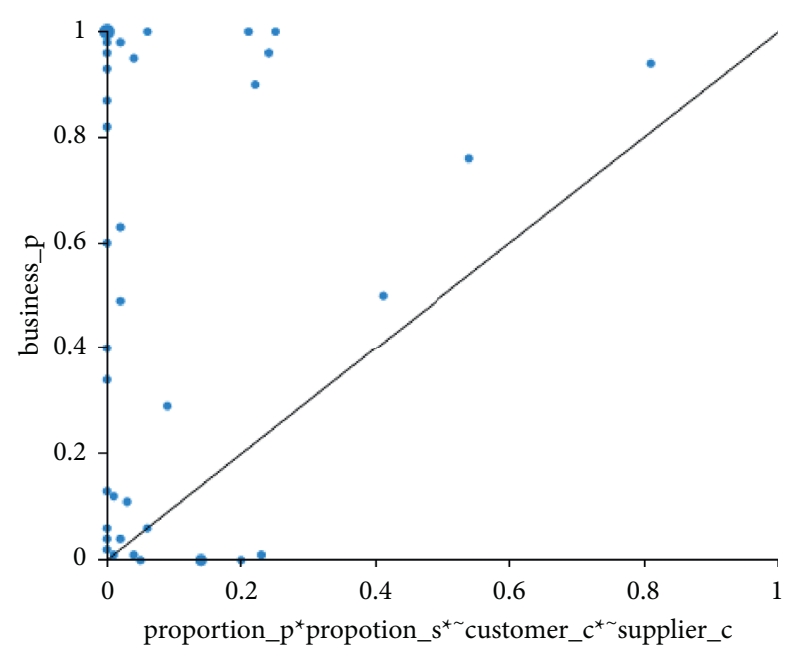

(a)

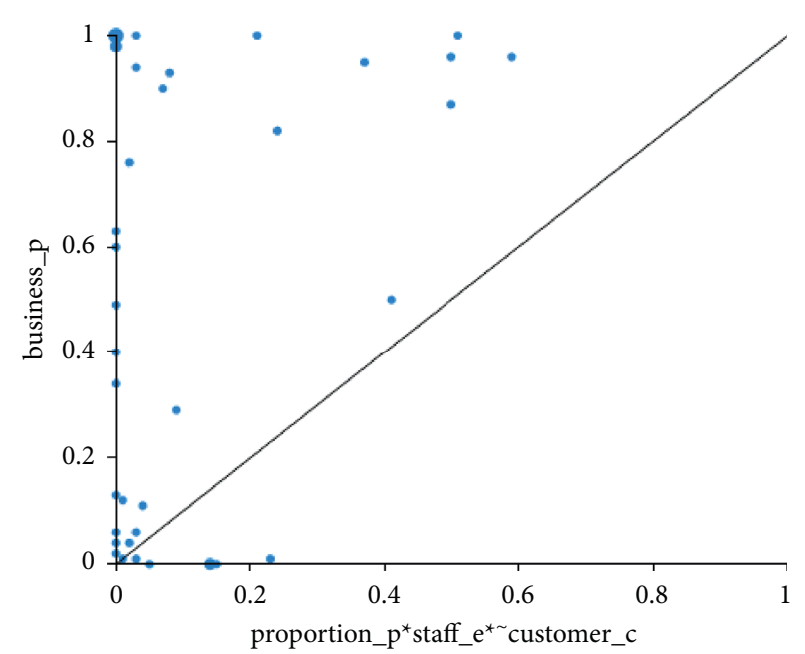

(b)

Figure 2: Configuration $X-Y$ scatter plot.

TABLE 4: Adjusted variable calibration anchors.

\begin{tabular}{lcccc}
\hline & Variables (in percentage) & & \multicolumn{2}{c}{ Anchor points } \\
& & Full membership & Intersection & Full nonmembership \\
\hline Outcome variable & Business performance & 8.99 & 4.93 & 1.55 \\
\hline & Customer concentration & 56.31 & 23.80 & 9.83 \\
Conditional variables & Supplier concentration & 49.10 & 21.09 & 11.32 \\
& Proportion of production personnel & 77.49 & 63.32 & 31.94 \\
& Proportion of sales personnel & 23.83 & 4.96 & 2.09 \\
& Staff education structure & 61.16 & 21.00 & 10.74 \\
\hline
\end{tabular}

TABLE 5: Analysis results of effective configuration solutions for high performance of manufacturing enterprises.

\begin{tabular}{lcc}
\hline Configuration & \multicolumn{2}{c}{ Solutions } \\
& 1 & 2 \\
\hline Customer concentration & $\otimes$ & $\otimes$ \\
Supplier concentration & $\otimes$ & $\bullet^{*}$ \\
Proportion of production personnel & $\bullet$ & $\bullet$ \\
Proportion of sales personnel & $\bullet$ & \\
Staff education structure & & $\bullet$ \\
Consistency & 0.77 & 0.77 \\
Raw coverage & 0.27 & 0.18 \\
Unique coverage & 0.16 & 0.07 \\
Solution consistency & 0.80 & \\
Solution coverage & 0.35 & \\
\hline
\end{tabular}

Note. ${ }^{*}$ indicates the inconsistency with the results in Table 3 . Bold values represent best accuracy.

4.3. Robustness Test. Gigerenzer et al. [25] argued that it is necessary to carry out robustness test to ensure the correctness of the results when using QCA method for empirical analysis. In this paper, according to the QCA robustness test method proposed by Ragin [27], the anchor points of the critical values (full membership, intersection, and full nonmembership) of each variable are adjusted. The three anchors of variables are changed from 75, 50, and 25 quantiles of sample data to 90,50 , and 10 quantiles, respectively, and the adjusted variable calibration points are obtained as shown in Table 4.

The empirical results obtained by reprocessing the sample data with fsQCA software are shown in Table 5. It can be found that, except for slight differences, the effective path from the original empirical results is basically unchanged. Thus, the reliability of the original empirical conclusion is verified.

\section{Conclusions and Managerial Insights}

To help with the transformation into intelligent manufacturing, this paper proposes a decision support model for managers to choose the appropriate configuration of supply chain concentration and staff structure. We employ the fuzzy set after a qualitative comparison analysis on the sample data and draw the following conclusions. First, when the supply chain concentration of manufacturing enterprises is decentralized, increasing the proportion of production personnel and sales personnel can improve the business performance of manufacturing enterprises, especially those more affected by the structure of production personnel. Second, when the customer concentration degree or supplier concentration degree is low, increasing the proportion of sales staff configuration and the staff structure of sales staff is conducive to improving the sales volume, thus improving the business performance of the enterprise. 
Third, when the customer concentration degree is high, or the supplier concentration degree is high, the production quantity of the enterprise will have higher requirements, improve the staff structure of production staff, and accelerate the output of the enterprise, which has a considerable promotion effect on improving the business performance of the enterprise. When an enterprise has a high proportion of production personnel and a low degree of customer concentration, the manufacturing enterprise is likely to be locked in the position of low value-added products, so it needs to upgrade the enterprise to obtain higher profits. At this point, enterprise decision makers should introduce talents and refine the knowledge structure of employees to improve enterprise performance.

Based on our empirical results, this paper proposes the following managerial insights. First, when manufacturing enterprises are at the low end of the value chain, enterprise decision makers should optimize the staff structure reasonably. For manufacturing enterprises, high proportion of production personnel and low degree of customer concentration are common characteristics. The possible reason is that most of China's manufacturing companies are still locked at the lower end of the global value chain. Accelerating the transformation and upgrading of the manufacturing industry and upgrading the core technology of the manufacturing industry are conducive to the reconstruction of the global value chain.

Second, when the degree of customer concentration or supplier concentration is low, improving the configuration of the proportion of sales staff and the employee structure of sales staff is conducive to increasing the sales volume of the enterprise and thus improving its business performance. Through the introduction of talents, accelerate the improvement of professional quality of employees, and use online marketing means to enhance the performance of intelligent manufacturing.

Third, when the customer concentration is high, or the supplier concentration is high, there are higher requirements on the production quantity of the enterprise. Improving production staff can significantly improve the business performance of the enterprise. When an enterprise has a high proportion of production personnel and a low degree of customer concentration, it is likely to be locked in the positioning of low value-added of products. Therefore, it is necessary to upgrade the enterprise. At this time, managers should improve the business performance by introducing talents and improve the knowledge structure of employees. Based on the market demand of intelligent manufacturing, the production performance of enterprises can be improved through intelligent matching and restructuring of supply chain.

In the future development trend, intelligent manufacturing will make more use of artificial intelligence technology and remote man-machine service, with higher innovation in technological innovation and significant improvement in economic output and information construction, but the growth in energy and environment optimization will be relatively slow [28]. Intelligent manufacturing will get more support of intelligent system optimization, intelligent system's ability to provide predictive views will be provided to make complex manufacturing model more acute, and the intelligent decision support system in a variety of manufacturing tasks, such as smart and continuous inspection, predictive maintenance, quality improvement, process optimization, and supply chain management provides a path [29] in task scheduling. Intelligent manufacturing has great potential in network collaboration, mass customization, sustainability, and flexibility. Customized production can better meet the needs of dynamic users, and network collaboration can significantly improve production efficiency [30]. Countries around the world have proposed intelligent manufacturing policies and put forward related architecture including its hierarchy and component elements. However, as far as implementation is concerned, there is a need to further expand and study the relationship between framework elements and specific application programmes [31].

\section{Data Availability}

The data used to support the findings of this study are available from the corresponding author upon request.

\section{Disclosure}

The funder had no role in the design of the paper, the collection of data, the analysis, the writing of the manuscript, or the decision to publish the results.

\section{Conflicts of Interest}

The author states that there are no conflicts of interest.

\section{Acknowledgments}

This study was financially supported by the National Social Science Program of China (Grant no. 20BJL125).

\section{References}

[1] L. Feng, X. H. Zhang, and K. G. Zhou, "Current problems in China's manufacturing and countermeasures for industry 4.0," EURASIP Journal on Wireless Communications and Networking, vol. 90, no. 2, pp. 1671-1678, 2018.

[2] Y. L. Zhao and C. C. Pei, "Technological innovation, industrial integration, and transformation and upgrading of manufacturing industry," Science \& Technology Progress and Policy, vol. 36, no. 11, pp. 70-76, 2019.

[3] S. Hertz, J. Hultman, and J. Wikner, "Linking corporate strategy and supply chain management," International Journal of Physical Distribution \& Logistics Management, vol. 11, no. 10, pp. 136-149, 2010.

[4] D. Lanier, W. F. Wempe, and Z. G. Zacharia, "Concentrated supply chain membership and financial performance: chainand firm-level perspectives," Journal of Operations Management, vol. 28, no. 1, pp. 1-16, 2010.

[5] S. Qrunfleh and M. Tarafdar, "Lean and agile supply chain strategies and supply chain responsiveness: the role of strategic supplier partnership and postponement," Supply Chain Management: International Journal, vol. 18, no. 6, pp. 571582, 2013. 
[6] P. Drucker, Innovation and Entrepreneurship, Routledge, England, UK, 2014.

[7] Z. L. Tian and C. H. Liu, "Customer concentration, key customer bargaining power and SME performance - an empirical study based on SME board manufacturing listed companies," Forecasting, vol. 34, no. 4, pp. 51-52, 2015.

[8] Q. Y. Huang and Y. F. Song, "Empirical study on the effect of supply chain concentration on the intensity of R\& D input of enterprises --- regulatory role of property right nature," $R \& D$ Management, vol. 31, no. 3, pp. 13-26, 2019.

[9] Z. C. Yang and Z. J. Wang, "Compensation incentives and corporate performance of executives based on factor-intensive production," Collected Essays on Finance and Economics, vol. 10, no. 2, pp. 97-102, 2008.

[10] S. S. Liu, Q. X. Zhou, and G. Chao, "High performance work system and organizational performance: an empirical study of chain industry in China," Chinese Journal of Management Science, vol. 9, no. 1, pp. 142-149, 2005.

[11] C. Lyu, F. H. Cao, Z. Z. Zhou, and H. L. Gao, "The influence of knowledge structure of senior management team on innovation performance of high-tech enterprises," Forum on Science and Technology in China, vol. 2, no. 10, pp. 174-181, 2018.

[12] J. Wang, X. Q. Xu, and Y. X. Sun, "Do government subsidies reflect "competition neutrality"? a qualitative comparative analysis based on fuzzy sets," Modern Economic Science, vol. 38, no. 2, pp. 125-126, 2016.

[13] M. Jian and T. J. Wong, "Propping through related party transactions," Review of Accounting Studies, vol. 15, no. 1, 2010.

[14] D. Dhaliwal, J. S. Judd, and M. Serfling, "Customer concentration risk and the cost of equity capital[J]," Journal of Accounting and Economics, vol. 61, no. 1, pp. 23-48, 2016.

[15] H. Cao and L. Tao, "The productivity performance of enterprise IT investment and the moderating effect of staff-based on the evidence of manufacturing listed companies," in Proceedings of the 2017 International Conference on Service Systems and Service Management, pp. 1-6, Dalian, China, June 2017.

[16] G. Xiao and J. Yang, "Does executive equity incentive promote enterprise upgrade --- empirical evidence from Chinese listed companies," Nankai Business Review, vol. 21, no. 3, pp. 66-75, 2018.

[17] B. Zhao, B. Y. Lin, and X. S. Zhang, "Influencing factors and countermeasures of industrial cluster upgrade based on quantitative analysis of Quanzhou industrial cluster," Science and Technology Management Research, vol. 34, no. 20, pp. 180-186, 2014.

[18] C. Wang and Y. S. Mao, "Enterprise upgrading path from OEM to ODM and OBM based on a comparative case study of seagull bathroom and Shenzhen Globe Union," China Industrial Economics, vol. 12, pp. 110-116, 2007.

[19] L. Poppo and T. Zenger, "Do formal contracts and relational governance function as substitutes or complements," Strategic Management Journal, vol. 23, no. 8, pp. 707-725, 2002.

[20] B. Rihoux and C. C. Ragin, Configurational Comparative Methods: Qualitative Comparative Analysis (QCA) and Related Techniques, Sage Publications, Thousand Oaks, CL, USA, 2008.

[21] A. Katz, M. Vom Hau, and J. Mahoney, "Explaining the great reversal in Spanish America: fuzzy-set analysis versus regression analysis," Sociological Methods \& Research, vol. 33, no. 4, pp. 539-573, 2005.
[22] G. Hu and M. Xu, "OFDI intensity, R\&D intensity and business performance of China's large and medium-sized industrial enterprises: a study from the perspective of mediating effect and moderating effect," Economist, vol. 4, pp. 88-95, 2016.

[23] C. Ragin and S. I. Strand, "Using qualitative comparative analysis to study causal order: comment on Caren and Panofsky," Sociological Methods \& Research, vol. 36, no. 4, pp. 431-441, 2008.

[24] C. Fiss, "Building better causal theories: a fuzzy set approach to typologies in organization research," Academy of Management Journal, vol. 54, no. 2, pp. 393-420, 2011.

[25] G. Gigerenzer and H. Brighton, "Homo heuristics: why biased minds make better inferences," Topics in Cognitive Science, vol. 1, no. 1, pp. 107-143, 2009.

[26] C. Ragin, Redesigning Social Inquiry: Fuzzy Sets and beyond, University of Chicago Press, Chicago, IL, USA, 2009.

[27] C. Ragin, "Set relations in social research: evaluating their consistency and coverage," Political Analysis, vol. 14, pp. 291-310, 2006.

[28] R. Agrawal, J. K. Jain, V. S. Yadav, V. K. Manupati, and L. Varela, "Recent advances in smart manufacturing and materials," 2021.

[29] A. Dvivedi, A. Sachdeva, R. Sindhwani, and R. Sahu, "Recent trends in industrial and production engineering," 2021.

[30] K. Palanikumar, E. Natarajan, R. Sengottuvelu, and J. P. Davim, "Futuristic trends in intelligent manufacturing," 2021.

[31] X. Y. Zhang and X. G. Ming, "Further expansion from smart manufacturing system (SMS) to smart manufacturing implementation system (SMIS): industrial application scenarios and evaluation," International Journal of Advanced Manufacturing Technology, vol. 33, 2021. 